\title{
State or Local Health Department
}

National Cancer Institute

\section{Source}

National Cancer Institute. State or Local Health Department. NCI Thesaurus. Code C19043.

A part of the public health system that includes administrative and service units concerned with the health of persons in specific jurisdictions, i.e., county or state. 